\title{
LA LEGISLACIÓN BÁSICA DE PROTECCIÓN DEL MEDIO AMBIENTE
}

\section{(PRIMER SEMESTRE 2017)}

\author{
LUCÍA CASADO CASADO
}

Profesora Titular de Derecho Administrativo

Universitat Rovira i Virgili

\section{Subdirectora}

Centre d'Estudis de Dret Ambiental de Tarragona (CEDAT)

\begin{abstract}
Sumario: 1. Introducción. 2. El nuevo texto refundido de la Ley de prevención y control integrados de la contaminación. 3. La reestructuración de los departamentos ministeriales: el nuevo Ministerio de Agricultura y Pesca, Alimentación y Medio Ambiente. 4. Novedades normativas en ámbitos sectoriales. 4.1. En materia de patrimonio natural y biodiversidad. 4.2. En materia de residuos. 4.3. En materia de aguas. 4.4. En materia de protección de la atmósfera.
\end{abstract}




\section{INTRODUCCIÓN}

Durante el período objeto de análisis (del 1 de octubre de 2016 al 30 de marzo de 2017), a nivel estatal, se ha recuperado la actividad normativa en materia ambiental, una vez constituido, el pasado mes de noviembre el nuevo gobierno, tras casi un año de gobierno en funciones. Ahora bien, la práctica totalidad de las normas adoptadas tienen rango reglamentario -con la única excepción del Real Decreto Legislativo 1/2016, de 16 de diciembre, por el que se aprueba el texto refundido de la Ley de prevención y control integrados de la contaminación-, y, por lo general, bien proceden a desarrollar determinados aspectos de normas de rango legal aún pendientes de desarrollo, o bien responden, no tanto a la aprobación de normas completamente nuevas, sino a la modificación de normas ya existentes, para mejorar la regulación recogida por las mismas.

El predominio de normas reglamentarias revela que sigue siendo la tónica predominante la aprobación de normas reglamentarias con carácter de legislación básica en materia de medio ambiente, posibilidad que, aunque admitida por el Tribunal Constitucional con carácter excepcional, "siempre que resulten imprescindibles y se justifiquen por su contenido técnico o por su carácter coyuntural, estacional o circunstancial y, en suma, sometido a cambios o variaciones frecuentes e inesperadas (SSTC 102/1995, de 26 de junio, FJ 8; y STC 306/2000, de 12 de diciembre, FJ 6)"', ha acabado generalizándose en materia ambiental. Entre las normas reglamentarias aprobadas en este período destacamos, en particular, las aprobadas en materia de patrimonio natural y biodiversidad, residuos, aguas y protección de la atmósfera, además de las que afectan a la estructura orgánica del Ministerio de Agricultura y Pesca, Alimentación y Medio Ambiente.

Asimismo, en el ámbito internacional, destaca la ratificación por España del Acuerdo de París, hecho en París el 12 de diciembre de 2015, que había sido firmado en Nueva York el día 22 de abril de $2016^{2}$, y cuyo objeto es reforzar la

\footnotetext{
${ }^{1}$ Vid., por ejemplo, la Sentencia 161/2014, de 7 de octubre de 2014, FJ $7^{\circ}$.

${ }^{2}$ Instrumento de Ratificación del Acuerdo de París, hecho en París el 12 de diciembre de 2015 (BOE núm. 28, de 2 de febrero de 2017).
} 
respuesta mundial a la amenaza del cambio climático, en el contexto del desarrollo sostenible y de los esfuerzos por erradicar la pobreza.

\section{EL NUEVO TEXTO REFUNDIDO DE LA LEY DE PREVENCIÓN Y CONTROL INTEGRADOS DE LA CONTAMINACIÓN}

El Gobierno, mediante el Real Decreto Legislativo 1/2016, de 16 de diciembre, de conformidad con la habilitación prevista en la disposición final $2^{a}$ de la Ley 5/2013, de 11 de junio, por la que se modificaba la Ley 16/2002, de 1 de julio, de prevención y control integrados de la contaminación ${ }^{3}$, ha aprobado el texto refundido de la Ley de prevención y control integrados de la contaminación, integrando en un único texto legal la Ley 16/2002 y sus sucesivas modificaciones ${ }^{4}$, con el fin de mejorar la calidad normativa y la seguridad jurídica en este ámbito. Este texto refundido, con arreglo a su disposición final $2^{2}$, tiene la consideración de legislación básica sobre protección del medio ambiente de acuerdo con lo establecido en el artículo 149.1.23 de la CE, si bien lo establecido en la disposición final $1^{\text {a }}$ y las referencias a la gestión de las cuencas intercomunitarias tienen su fundamento constitucional en el artículo 149.1.22 de la $\mathrm{CE}$, que otorga al Estado la competencia exclusiva sobre la legislación, ordenación y concesión de recursos y aprovechamientos hidráulicos cuando las aguas discurran por más de una comunidad autónoma.

Tal como se pone de manifiesto en su Preámbulo, "En aras de la coherencia normativa que deriva del principio constitucional de seguridad jurídica, además de recoger en un único instrumento normativo la cambiante regulación en la materia, se ha hecho preciso armonizar el contenido de los artículos, de manera que se ha ajustado la numeración de los artículos y, por lo tanto, las remisiones

\footnotetext{
${ }^{3}$ La disposición final $2^{a}$ de la Ley 5/2013 fue modificada por la Ley 21/2015, de 20 de julio, por la que se modificaba la Ley 43/2003, de 21 de noviembre, de montes.

${ }^{4}$ Producidas a través de las siguientes normas de rango legal: Ley 1/2005, de 9 de marzo, por la que se regula el régimen del comercio de derechos de emisión de gases de efecto invernadero; Ley 27/2006, de 18 de julio, por la que se regulan los derechos de acceso a la información, de participación pública y de acceso a la justicia en materia de medio ambiente; Ley 34/2007, de 15 de noviembre de calidad del aire y protección de la atmósfera; Ley 42/2007, de 13 de diciembre, del patrimonio natural y de la biodiversidad; Ley 40/2010, de 29 de diciembre de almacenamiento geológico de dióxido de carbono; Real Decretoley 8/2011, de 1 de julio de medidas de apoyo a los deudores hipotecarios, de control del gasto público y cancelación de deudas con empresas y autónomos contraídas por las entidades locales, de fomento de la actividad empresarial e impulso de la rehabilitación y de simplificación administrativa; y Ley 5/2013, de 11 de junio, por la que se modifican la Ley 16/2002, de 1 de julio, de prevención y control integrados de la contaminación y la Ley 22/2011, de 28 de julio, de residuos y suelos contaminados.
} 
y concordancias entre ellos". Además, este Real Decreto Legislativo actualiza todas las referencias normativas incluidas en el mismo y, respetando las normas que han de ser objeto de refundición, introduce algunos retoques menores para lograr una norma con la mayor claridad posible 5 .

Entre los cambios ${ }^{6}$ que se introducen en este texto refundido destacamos especialmente dos, relativos a la coordinación de la autorización ambiental integrada con el régimen aplicable a las actividades clasificadas y al régimen sancionador. Por un lado, el artículo 29 del texto refundido modifica las previsiones anteriormente contenidas en el artículo 28 de la Ley 16/2002 con relación a la coordinación entre la autorización ambiental integrada y el régimen aplicable en materia de actividades clasificadas. El nuevo artículo 29 prevé que el procedimiento para el otorgamiento de la autorización ambiental integrada "prevalecerá sobre cualquier otro medio de intervención administrativa en la actividad de los ciudadanos que puedan establecer las Administraciones competentes para el ejercicio de actividades molestas insalubres, nocivas y peligrosas". En cambio, el artículo 28 de la Ley 16/2002, preveía que la autorización ambiental integrada "sustituirá a los medios de intervención administrativa en la actividad de los ciudadanos que puedan establecer las Administraciones competentes para el ejercicio de actividades molestas, insalubres, nocivas y peligrosas", aunque precisaba -en el apartado 2 del mismo art. 28- que esto se entendía "sin perjuicio de las normas autonómicas sobre actividades clasificadas que, en su caso, fueran aplicables" -precisión que ahora ha desaparecido en el art. 29-, por lo que respetaba la posibilidad de que la normativa autonómica mantuviese la existencia de ambas autorizaciones. Ahora, se afirma la prevalencia -no la sustitución- de la autorización ambiental integrada sobre las licencias de actividades clasificadas que puedan establecer las administraciones competentes. Por otra parte, se mantiene en el artículo 29 del texto refundido la previsión anteriormente recogida en el artículo 28 de la Ley

\footnotetext{
${ }^{5}$ Así lo pone de manifiesto Blanca Lozano Cutanda, "El nuevo texto refundido de la ley de prevención y control integrados de la contaminación: mejora normativa y algún retoque", en Diario La Ley, núm. 8947, Sección Tribunal, 23 de marzo de 2017, p. 2.

${ }^{6}$ Puede verse un análisis más completo de las novedades incorporadas por este texto refundido en los siguientes trabajos: Antonio Cano Murcia, "Notas y comentarios al Texto Refundido de la Ley de Prevención y Control Integrados de la Contaminación", en El Consultor de los Ayuntamientos, núm. 3, 2017, de 15 de febrero de 2017, pp. 1-6; y Lozano Cutanda, "El nuevo..." cit., pp. 1-5.
} 
16/2002 dirigida a establecer que "la autorización ambiental integrada será, en su caso, vinculante para la autoridad local cuando implique la denegación del ejercicio de las actividades o la imposición de medidas correctoras, así como en lo referente a todos los aspectos medioambientales recogidos en el artículo 22".

Por otro, se introducen algunas modificaciones en el régimen sancionador. Así, en el artículo 31, en sus apartados 2 y 3, que recogen las infracciones muy graves y graves, se introduce una precisión en cuanto a la tipificación de las infracciones recogidas en su apartado c) y se indica que constituye una infracción muy grave, incumplir las obligaciones derivadas de las medidas provisionales previstas en el artículo 35 de esta ley "cuando suponga un peligro grave para la salud de las personas o el medio ambiente" -inciso ahora añadido, no recogido en el anterior art. 30.2.c) de la Ley 16/2002-; y una infracción grave incumplir las obligaciones derivadas de las medidas provisionales previstas en el artículo 35 "cuando no suponga un peligro grave para la salud de las personas o el medio ambiente" -inciso también añadido, tampoco incluido en el anterior art. 30.3.c) de la Ley 16/2002-. Por otra parte, ahora el texto refundido impone, en su artículo 36.1, a todos los infractores la obligación de "adoptar las medidas complementarias que el órgano competente estime necesarias para volver a asegurar el cumplimiento de las condiciones de la autorización ambiental integrada y para evitar otros posibles incidentes o accidentes", novedad importante, ya que, con anterioridad, la Ley 16/2002, únicamente imponía esta obligación -en su art. 31.1.b)- a quienes hubieran cometido una infracción grave.

\section{LA REESTRUCTURACIÓN DE LOS DEPARTAMENTOS MINISTERIALES: EL NUEVO MINISTERIO DE AGRICULTURA Y PESCA, ALIMENTACIÓN Y MEDIO AMBIENTE}

En materia organizativa, a través del Real Decreto 415/2016, de 3 de noviembre, se han reestructurado los departamentos ministeriales. Desde la perspectiva que aquí nos interesa, el grueso de competencias ambientales se concentra ahora en el Ministerio de Agricultura y Pesca, Alimentación y Medio Ambiente, quedando suprimido el anterior Ministerio de Agricultura, Alimentación y Medio Ambiente. A dicho Ministerio corresponde la propuesta y ejecución de la política del Gobierno en materia de recursos agrícolas, ganaderos y pesqueros, de 
industria agroalimentaria y de desarrollo rural; y la propuesta y ejecución de la política del Gobierno en materia de medio ambiente.

La estructura orgánica básica del nuevo Ministerio de Agricultura y Pesca, Alimentación y Medio ambiente se ha definido en el Real Decreto 424/2016, de 11 de noviembre, por el que se establece la estructura orgánica básica de todos los departamentos ministeriales. Este Ministerio se estructura en los siguientes órganos superiores y directivos: la Secretaría de Estado de Medio Ambiente, de la que dependen la Dirección General del Agua, la Oficina Española del Cambio Climático -con rango de Dirección General-, la Dirección General de Calidad y Evaluación Ambiental y Medio Natural y la Dirección General de Sostenibilidad de la Costa y del Mar; la Secretaría General de Agricultura y Alimentación, de la que dependen la Dirección General de Producciones y Mercados Agrarios, la Dirección General de Sanidad de la Producción Agraria, la Dirección General de la Industria Alimentaria y la Dirección General de Desarrollo Rural y Política Forestal; y la Subsecretaría de Agricultura y Pesca, Alimentación y Medio Ambiente, de la que dependen la Secretaría General Técnica y la Dirección General de Servicios; y la Secretaría General de Pesca, de la que dependen la Dirección General de Ordenación Pesquera y la Dirección General de Recursos Pesqueros y Acuicultura.

\section{NOVEDADES NORMATIVAS EN ÁMBITOS SECTORIALES}

En el período objeto de análisis se han aprobado numerosas normas de rango reglamentario en materia ambiental, en ámbitos sectoriales diversos. Dada la imposibilidad de analizarlas todas ellas, nos limitamos a destacar aquellas que nos han parecido especialmente relevantes en materia de patrimonio natural y biodiversidad, residuos, aguas y protección de la atmósfera.

\subsection{En materia de patrimonio natural y biodiversidad}

En este ámbito, cabe destacar, en primer lugar, dos normas aprobadas en materia de parques nacionales, dictadas al amparo del artículo 149.1.23 de la $\mathrm{CE}$, que atribuye al Estado la competencia de legislación básica sobre protección del medio ambiente, sin perjuicio de las facultades de las comunidades 
autónomas de establecer normas adicionales de protección7. Por una parte, el Real Decreto 389/2016, de 22 de octubre, por el que se aprueba el Plan Director de la Red de Parques Nacionales, y que sustituye y deroga al anteriormente regulado por el Real Decreto 1803/1999, de 26 de noviembre, con el fin de adaptarlo a las nuevas previsiones de la Ley 30/2014, de 3 de diciembre, de parques nacionales ${ }^{8}$. Este Plan constituye un instrumento básico de ordenación de la Red de Parques Nacionales y se configura como "el más elevado instrumento de planificación y ordenación de estos espacios de carácter básico" (art. 19 Ley 30/2014) y tiene "el carácter de directrices básicas para la planificación, conservación y coordinación de los parques nacionales de acuerdo con lo dispuesto en el artículo 19, apartados 1.d) y 2 de la Ley 30/2014, de 3 de diciembre, de Parques Nacionales, y de directrices básicas de la legislación de protección del medio natural conforme a lo dispuesto en el artículo 17, apartados 2 y 3 de la Ley 42/2007, de 13 de diciembre, del Patrimonio Natural y de la Biodiversidad" (art. 2 Real Decreto 389/2016). Los Planes Rectores de Uso y Gestión vigentes deberán adaptarse a este Plan Director en el plazo de dos años desde su entrada en vigor, de conformidad con lo dispuesto en la disposición adicional 3a de la Ley 30/2014; y los que se encuentren en fase de elaboración por la administración competente de cada parque nacional, se ajustarán a este Plan Director.

Por otra, el Real Decreto 598/2016, de 5 de diciembre, por el que se regula la composición, funciones y funcionamiento del Consejo de la Red de Parques

\footnotetext{
${ }^{7}$ Aunque con algún matiz en el caso del Real Decreto 389/2016, de 22 de octubre, cuya disposición final $1^{a}$ también invoca otros títulos competenciales en relación con determinadas materias. En efecto, prevé que la planificación socioeconómica de los parques nacionales prevista en el nuevo Plan Director se dicta al amparo del artículo 149.1.13 de la CE, que atribuye al Estado la competencia exclusiva en materia de bases y coordinación de la planificación general de la actividad económica; y que los criterios recogidos en el Plan Director para determinar la existencia de un grave peligro para la integridad y la seguridad de un parque nacional, así como las directrices para las actuaciones en las situaciones de estado de emergencia declarado, se amparan en la competencia en materia de seguridad pública, atribuida al Estado con carácter exclusivo por el artículo 149.1.29 de la CE.

${ }^{8}$ Pueden verse algunas de las novedades de este Plan Director de la Red de Parques Nacionales, en particular en cuanto a los derechos de los particulares afectados por la declaración de parque nacional, en Blanca Lozano Cutanda, "Real Decreto 389/2016: los derechos de los particulares en los parques nacionales según el nuevo plan director", en Análisis GA\&P, marzo 2017 (〈http://www.gomezacebopombo.com/media/k2/attachments/real-decreto-389-2016-los-derechos-de-los-particulares-en-losparques-nacionales-segun-el-nuevo-plan-director.pdf [Última consulta, 9 de mayo de 2017]).
} 
Nacionales, órgano colegiado de carácter consultivo, adscrito al Ministerio de Agricultura y Pesca, Alimentación y Medio Ambiente.

En segundo lugar, resulta de referencia obligada el Real Decreto 599/2016, de 5 de diciembre, por el que se regula la licencia de uso de la marca "Reservas de la Biosfera Española". Desde el punto de vista del título competencial estatal que sirve de base para la aprobación de esta norma, resulta llamativo y suscita una cierta perplejidad lo establecido por su disposición final 1a, ya que, si bien declara que "se dicta en virtud de la competencia estatal en materia de legislación básica sobre protección del medio ambiente de conformidad con lo dispuesto en el artículo 149.1.23 de la Constitución", a continuación afirma que "no constituye legislación básica sino que se dicta en ejercicio de las competencias de desarrollo y ejecución del artículo 149.1.23 que corresponden al Estado por el alcance internacional de dicha materia" . En cuanto a su contenido, este Real Decreto regula la licencia de uso de la marca "Reservas de la Biosfera Españolas", estableciendo las normas y los requisitos para su concesión, mantenimiento y extinción. El objeto de esta marca es destacar y diferenciar "aquellos productos naturales y artesanales de los territorios reconocidos como Reservas de la Biosfera y aquellos productos elaborados $\mathrm{y} / \mathrm{o}$ servicios de empresas dadas de alta en alguno de los municipios que pertenecen a las Reservas y que contribuyan a una o más de las funciones básicas que deben cumplir las Reservas de la Biosfera (conservación, desarrollo y apoyo logístico), así como que estén de acuerdo con el plan de gestión de la correspondiente Reserva de la Biosfera, respetando así las singularidades de cada una de ellas" (art. 3). Para ello, los productos y/o servicios han de cumplir con una serie de criterios y han de proveerse con la calidad definidos en este reglamento, además

\footnotetext{
${ }^{9}$ No aporta mayores aclaraciones en este punto la Memoria abreviada de análisis del impacto normativo del Proyecto de Orden por la que se regula la licencia de uso de la marca "Reservas de la biosfera españolas", que se limita a prever que "la regulación del régimen jurídico y el procedimiento de concesión de la licencia de uso de la citada marca debe realizarse en una norma en base a la competencia estatal en materia de legislación básica sobre protección del medio ambiente, prevista por el artículo 149.1.23 de la Constitución, si bien, en este caso, no se trata de legislación básica sino que la orden se dicta en ejercicio de las competencias de desarrollo y ejecución del citado artículo constitucional que corresponden al estado por el alcance internacional de dicha materia" (p. 5). Tampoco el Consejo de Estado ha puesto en cuestión el título competencial invocado por el Estado, en su Dictamen 235/2016, de 14 de abril de 2016, afirmando que "El título competencial previsto en el preámbulo -el artículo 149.1.23 de la Constitución española, en ejercicio de las competencias de desarrollo y ejecución de dicho artículo que corresponden al Estado por el alcance internacional de dicha materia- es correcto y no suscita ninguna problemática al tratarse de una marca de ámbito nacional" (apartado III).
} 
de ser ambientalmente respetuosos. Asimismo, cualquier producto o servicio susceptibles de ser diferenciados por las marcas específicas de cada reserva podrán a su vez obtener la licencia de uso de la Marca "Reservas de la Biosfera Españolas", siempre y cuando cumplan con las premisas básicas de calidad y procedencia descritas en este reglamento. El Organismo Autónomo Parques Nacionales es el titular de esta marca, en virtud de su inscripción en la Oficina Española de Patentes y Marcas; y el órgano de control responsable del buen uso de la marca, como titular de la misma.

En tercer lugar, mediante el Real Decreto 124/2017, de 24 de febrero, relativo al acceso a los recursos genéticos procedentes de taxones silvestres y al control de la utilización ${ }^{10}$, se desarrollan los artículos $71,72,74,80$ y 81 de la Ley 42/2007, de 13 de diciembre, del patrimonio natural y de la biodiversidad; y se asegura la correcta utilización de los recursos genéticos, de conformidad con el Reglamento (UE) N.. 511/2014 del Parlamento Europeo y del Consejo, de 16 de abril, relativo a las medidas de cumplimiento de los usuarios del Protocolo de Nagoya en la Unión y con el Reglamento de ejecución (UE) 2015/1866 de la Comisión, de 13 de octubre de 2015, por el que se establecen normas detalladas para la aplicación del Reglamento (UE) N. 511/2014. Asimismo, se establece adicionalmente el sistema estatal de información sobre acceso y utilización de los recursos genéticos y conocimientos tradicionales asociados en España, y se crea y regula el Comité sobre acceso y utilización de los recursos genéticos y conocimientos tradicionales asociados a los recursos genéticos en España.

Por último, mediante el Real Decreto 199/2017, de 3 de marzo, se ha aprobado el Reglamento del Programa Nacional de Conservación y Utilización Sostenible de los Recursos Fitogenéticos para la Agricultura y la Alimentación, en desarrollo de lo establecido por los artículos 48, 49, 50 y 51 de la Ley 30/2006, de 26 de julio, de semillas y plantas de vivero y de recursos fitogenéticos, y se ha creado la Comisión del Programa Nacional de Recursos Fitogenéticos para la Agricultura y la Alimentación ${ }^{11}$.

\footnotetext{
${ }^{10}$ Este Real Decreto también tiene carácter de legislación básica sobre protección del medio ambiente, de conformidad con lo dispuesto en el artículo 149.1. 23. ${ }^{\mathrm{a}}$ de la CE (disposición final 2a).

${ }^{11}$ Con arreglo a su disposición final $1^{\mathrm{a}}$, este Real Decreto se dicta al amparo de lo dispuesto en el artículo 149. 1, apartados 15 y 23, de la CE, que atribuye al Estado competencia exclusiva sobre, respectivamente, fomento y coordinación general de la investigación científica y técnica, y legislación básica sobre
} 


\subsection{En materia de residuos}

En materia de residuos, resulta de referencia obligada el Real Decreto 20/2017, de 20 de enero, sobre los vehículos al final de su vida útil, que tiene la consideración de legislación básica sobre planificación general de la actividad económica y sobre protección del medio ambiente, conforme a lo dispuesto en el artículo 149.1.13 y 23 de la CE. Este Real Decreto deroga al anterior Real Decreto 1383/2002, de 20 de diciembre, sobre gestión de vehículos al final de su vida útil, que incorporó al ordenamiento jurídico español la Directiva 2000/53/CE del Parlamento Europeo y del Consejo, de 18 de septiembre de 2000, relativa a los vehículos al final de su vida útil.

La derogación del Real Decreto 1383/2002 y su sustitución por el nuevo Real Decreto 20/2017 se justifica por una serie de circunstancias que han tenido lugar en el tiempo transcurrido desde su adopción: la aprobación de la Ley 22/2011, de 28 de julio, de residuos y suelos contaminados, que ha introducido modificaciones relevantes en el régimen aplicable a la producción y gestión de residuos, que hace necesaria la adaptación a sus previsiones de las normas reglamentarias de desarrollo que se adopten; la adopción por parte de la Comisión de la Decisión 2005/293, de 1 de abril de 2005, por la que se establecen normas de desarrollo para controlar el cumplimiento de los objetivos de reutilización y valorización así como de reutilización y reciclado fijados en la Directiva 2000/53/CE; y la constatación, gracias a la experiencia adquirida durante su aplicación, de la existencia de algunos aspectos de la regulación que necesitan ser mejorados, como la definición del ámbito de aplicación de la norma y su coherencia con los regímenes de otros flujos de residuos.

Partiendo de estas premisas, el Real Decreto 20/2017 se aprueba con el objeto de establecer medidas destinadas a la prevención de la generación de residuos procedentes de vehículos y a la recogida, a la preparación para la reutilización, al reciclado y otras formas de valorización de los vehículos al final de su vida útil, incluidos sus componentes, para así reducir la eliminación de residuos y mejorar

protección del medio ambiente, salvo los preceptos relativos al mantenimiento y conservación de los recursos fitogenéticos, que se dictan al amparo de lo dispuesto en el artículo 149.1.13. ${ }^{\text {a }}$ de la Constitución Española, que atribuye al Estado competencia exclusiva sobre las bases y coordinación de la planificación general de la actividad económica. 
la eficacia en la protección de la salud humana y del medio ambiente a lo largo del ciclo de vida de los vehículos. De esta forma, se regulan, adaptan y sistematizan todos los aspectos relacionados con los vehículos al final de su vida útil, de conformidad con la Directiva 2000/53/CE y la Ley 22/2011. En esencia, tal como se pone de manifiesto en su Preámbulo, se mantiene la regulación preexistente sobre los vehículos al final de su vida útil y se conservan sus elementos fundamentales: la definición de vehículo; las obligaciones de los productores o fabricantes de vehículos; la obligación de los usuarios de entregar los vehículos a un centro de tratamiento, bien directamente, bien a través de una instalación de recepción; la obligación de documentar la entrega a través del certificado de destrucción que acredita el fin de la vida útil del vehículo; la tramitación por los centros de tratamiento de la baja del vehículo, de conformidad por la Orden INT/624/2008, de 26 de febrero; la exigencia del cumplimiento de requisitos técnicos de almacenamiento y tratamiento; y la obligación de los agentes económicos de cumplimiento de objetivos de preparación para la reutilización, reciclado y valorización.

Ahora bien, también se introducen novedades con respecto al Real Decreto que se deroga ${ }^{12}$. Las principales novedades derivan de la necesidad de adaptar sus previsiones a la Ley 22/2011, en especial, en lo que respecta a la jerarquía de residuos, a la responsabilidad ampliada del productor y a las obligaciones de información. Así, se precisa su ámbito de aplicación; se regulan con mayor detalle las operaciones que deben realizar los centros autorizados para el tratamiento de los vehículos al final de su vida útil y los requisitos que deben cumplir sus instalaciones; se adoptan medidas para evitar que se produzca una doble financiación de la gestión de los vehículos o de sus componentes; se completan algunas previsiones sobre las obligaciones a las que quedan sometidos los productores y otros agentes económicos, incluidas las de información, así como sobre el régimen sancionador; se adecua este flujo de residuos a la Ley 22/2011, en especial incluyendo la preparación para la

\footnotetext{
${ }^{12}$ Sobre las novedades introducidas por este Real Decreto, vid. Pedro Poveda Gómez y Blanca Lozano Cutanda, "Real Decreto 20/2017, sobre los vehículos al final de su vida útil: análisis de sus novedades", en Análisis GA\&P, febrero 2017 (〈http://www.gomezacebo-pombo.com/media/k2/attachments/real-decreto20-2017-sobre-los-vehiculos-al-final-de-su-vida-util-analisis-de-sus-novedades_2.pdf) [Última consulta, 9 de mayo de 2017]).
} 
reutilización como tratamiento y adaptando los sistemas de responsabilidad ampliada del productor del producto a lo previsto en su título IV; y se añade una disposición adicional para regular la cesión temporal de vehículos al final de su vida útil dados de baja definitiva en la Dirección General de Tráfico para fines de formación, investigación, protección civil o simulacros.

\subsection{En materia de aguas}

En el ámbito de las aguas, la norma más relevante aprobada en este período es el Real Decreto 638/2016, de 9 de diciembre, a través del cual se modifican el Real Decreto 849/1986, de 11 de abril, por el que se aprueba el Reglamento del dominio público hidráulico (en adelante, RDPH), el Real Decreto 907/2007, de 6 de julio, por el que se aprueba el Reglamento de la planificación hidrológica (RPH), la Orden ARM/2656/2008, de 10 de septiembre, por la que se aprueba la instrucción de planificación hidrológica, el Real Decreto 903/2010, de 9 de julio, de evaluación y gestión de riesgos de inundación, y el Real Decreto 817/2015, de 11 de septiembre, por el que se establecen los criterios de seguimiento y evaluación del estado de las aguas superficiales y las normas de calidad ambiental ${ }^{13}$.

Las modificaciones afectan a cuatro ámbitos de actuación esenciales, caracterizados, como se indica en la Memoria del análisis de impacto normativo de este Real Decreto, "por un eje conductor común, que es la experiencia adquirida en la aplicación de los Planes Hidrológicos de cuenca, de acuerdo con los calendarios establecidos en la Directiva 2000/60 marco del agua y los Planes de gestión del riesgo de inundación, de acuerdo con la Directiva 2007/60 de evaluación y gestión de los riesgos de inundación”: gestión del riesgo de inundaciones, caudales ecológicos, reservas hidrológicas y vertidos y calidad de las aguas. Con estas modificaciones se persiguen los siguientes objetivos:

\footnotetext{
${ }^{13}$ Con arreglo a su disposición final $1^{\text {a }}$, el Real Decreto 638/2016 tiene carácter de legislación básica sobre protección del medio ambiente, de conformidad con lo dispuesto en el artículo 149.1.23 CE, salvo los apartados uno a ocho, once a trece, treinta y uno y treinta y dos del artículo primero, que se dictan conjuntamente al amparo del 149.1.29 de la Constitución, que atribuye al Estado la competencia exclusiva sobre seguridad pública; y el apartado dieciséis en lo relativo al artículo 244 ter.2 y siguientes; el apartado diecinueve en lo relativo al artículo 254.1 y 254 bis.1; y los apartados veintiséis y veintisiete, todos ellos del artículo primero, que se dictan en virtud del artículo 149.1.22 CE, que atribuye al Estado la competencia exclusiva sobre la legislación, ordenación y concesión de recursos y aprovechamientos hidráulicos cuando las aguas discurran por más de una comunidad autónoma.
} 
mejorar el tratamiento de la gestión del riesgo de inundación, mejorar la definición y el régimen de cumplimiento de los caudales ecológicos, configurar el régimen jurídico de las reservas hidrológicas para proceder a la declaración de las reservas hidrológicas existentes en coordinación con los Planes Hidrológicos del segundo ciclo, y establecer las bases del censo nacional de vertidos.

En primer lugar, en cuanto a la gestión del riesgo de inundaciones, esta modificación actualiza el marco normativo vigente y mejora el tratamiento de la gestión del riesgo de inundación, resolviendo determinadas lagunas existentes en la normativa vigente, mejorando su regulación y garantizando la adecuada implantación y coordinación de los Planes hidrológicos de cuenca y los Planes de gestión del riesgo de inundación. De las modificaciones introducidas en esta materia destaca la introducción de una regulación detallada de los usos y construcciones prohibidos y permitidos en las zonas inundables de los cauces del dominio público hidráulico. En particular, se concretan cuáles son los usos y construcciones que no podrán ser autorizados en las zonas de flujo preferente según se trate de suelo rural o urbanizado-, incluyendo determinados supuestos excepcionales; y en el resto de zonas inundables ${ }^{14}$.

En segundo lugar, en relación con los caudales ecológicos, se precisan y mejoran determinados aspectos de su régimen jurídico, tanto de su definición jurídica, como de su mantenimiento, control y seguimiento por los distintos organismos de cuenca.

En tercer lugar, en materia de reservas hidrológicas, se introduce una nueva regulación, por medio de la modificación del $\mathrm{RDPH}$, que mejora la definición de esta figura y las medidas de gestión asociadas. En particular, se definen las características para declarar las reservas hidrológicas y los conceptos de los subtipos que las integran; se determina el régimen de protección de las reservas hidrológicas y el conjunto de medidas para la gestión de las mismas; y se define el Catálogo Nacional de Reservas Hidrológicas para dar soporte a toda la

\footnotetext{
${ }^{14}$ Sobre esta cuestión, vid. Blanca Lozano Cutanda y Carlos Vázquez Cobos, "Real Decreto 638/2016: regulación de los usos y construcciones en las zonas inundables de los cauces", en Análisis GA\&P, marzo 2017 (〈http://www.gomezacebo-pombo.com/media/k2/attachments/real-decreto-638-2016-regulaciyn-delos-usos-y-construcciones-en-las-zonas-inundables-de-los-cauces.pdf) [Última consulta, 9 de mayo de 2017]).
} 
información técnica que posibilite la adecuada descripción física de las reservas hidrológicas.

Por último, con relación a los vertidos, las modificaciones realizadas desarrollan aspectos relativos a la organización y funcionamiento del Censo Nacional de Vertidos, para adaptarse a la Ley 27/2006, de 18 de julio, reguladora de los derechos de acceso a la información, de participación pública y acceso a la justicia en materia de medio ambiente. Además, se concreta el destino del canon de control de vertido para reforzar su carácter finalista. Por último, con otras modificaciones relativas a los vertidos, se pretende aumentar la eficacia de la Administración, mediante la simplificación de los procedimientos y la reducción de cargas administrativas para los titulares de vertidos poco contaminantes y mejorar la protección de las aguas frente a vertidos generados por residuos industriales o mineros.

En materia de aguas, también puede destacarse la Orden AAA/1760/2016, de 28 de octubre, por la que se regula la estructura informática del Registro de Aguas y de la Base Central del Agua. A través de esta norma, de aplicación al Ministerio de Agricultura y Pesca, Alimentación y Medio Ambiente, los Organismos de cuenca y las Administraciones hidráulicas de las comunidades autónomas que tengan transferidas sus competencias, se determina la estructura informática que conforma el Registro de Aguas electrónico, regulado mediante el RDPH, desde su modificación por el Real Decreto 670/2013, de 6 de septiembre; y el contenido, la estructura informática y los modos de interoperabilidad de la Base Central del Agua con los sistemas de información que forman parte de la misma.

\subsection{En materia de protección de la atmósfera}

A través del Real Decreto 39/2017, de 27 de enero, se ha modificado el Real Decreto 102/2011, de 28 de enero, relativo a la mejora de la calidad del aire, que define y establece objetivos de calidad del aire para los contaminantes atmosféricos con más incidencia en la salud de las personas y en el medio ambiente; y, además, regula la evaluación, el mantenimiento y la mejora de la calidad del aire, con el establecimiento de métodos y criterios comunes de evaluación, y determina la información que debe ser intercambiada entre las 
administraciones públicas para el cumplimiento del deber de información a la Comisión Europea, así como la información que debe ser puesta a disposición del público ${ }^{15}$.

Esta modificación se justifica en tres razones fundamentales. En primer lugar, en la necesidad de incorporar al ordenamiento jurídico español la Directiva adoptada por la Comisión Europea 2015/1480, de 28 de agosto de 2015, por la que se modifican varios anexos de las Directivas 2004/107/CE del Parlamento Europeo y del Consejo, de 15 de diciembre de 2004, relativa al arsénico, el cadmio, el mercurio, el níquel y los hidrocarburos aromáticos policíclicos en el aire ambiente, y 2008/50/CE del Parlamento Europeo y del Consejo, de 21 de mayo de 2008, relativa a la calidad del aire ambiente y a una atmósfera más limpia en Europa. En ellas se establecen las normas relativas a los métodos de referencia, la validación de datos y la ubicación de los puntos de medición, para la evaluación de la calidad del aire ambiente, que deben ser incorporadas.

En segundo lugar, en la voluntad de eliminar una obligación que se había incorporado en el Real Decreto 812/2007, de 22 de junio, sobre evaluación y gestión de la calidad del aire ambiente en relación con el arsénico, el cadmio, el mercurio, el níquel y los hidrocarburos aromáticos policíclicos, y mantenido en el Real Decreto 102/2011, de medición del mercurio particulado y del mercurio gaseoso divalente, a pesar de que esta medición se recogía como una mera recomendación en la Directiva 2004/107/CE.

En tercer lugar, en la necesidad de corregir un error en la transposición de la Directiva 2008/50/CE, consistente en la confusión entre i-Hexano e i-Hexeno cometida en el apartado II del anexo XI.

A la vista de lo expuesto, las principales modificaciones que comporta este Real Decreto se refieren a los objetivos de calidad de los datos relativos al benzo(a)pireno, arsénico, cadmio y níquel, hidrocarburos aromáticos policíclicos (HAP) distintos del benzo(a)pireno, mercurio gaseoso total y depósitos totales. Asimismo, se pretende garantizar la adecuada evaluación de la calidad del aire

\footnotetext{
${ }^{15}$ El Real Decreto 102/2011, con arreglo a su disposición final $2^{\mathrm{a}}$, se dicta al amparo de las competencias exclusivas que al Estado otorga el artículo 149.1.16 y 23 de la Constitución, en materia de bases y coordinación general de la sanidad y de legislación básica sobre protección del medio ambiente.
} 
ambiente en lo que respecta al dióxido de azufre, dióxido de nitrógeno y óxidos de nitrógeno, monóxido de carbono, benceno, partículas y plomo, así como la microimplantación de los puntos de medición de dichos contaminantes, y regular los requisitos para la documentación y reevaluación de la elección de los emplazamientos. Por otro lado, las modificaciones también afectan a los métodos de referencia para la evaluación de las concentraciones de dióxido de azufre, dióxido de nitrógeno y óxidos de nitrógeno, partículas (PM10 y PM2,5), plomo, benceno, monóxido de carbono y ozono, arsénico, cadmio, mercurio, níquel e HAP; la normalización e informes de ensayo; los criterios de determinación del número mínimo de puntos para la medición fija de las concentraciones de ozono; la rectificación de la necesidad de determinación de mercurio particulado y de mercurio gaseoso divalente; y el establecimiento de las bases para el futuro desarrollo reglamentario de un índice de calidad del aire nacional.

Además, se concretan las competencias del Ministerio de Agricultura y Pesca, Alimentación y Medio Ambiente, a través de la Agencia Estatal de Meteorología, en lo que se refiere a información sobre la superación de los umbrales establecidos en las estaciones de medición bajo su gestión.

En materia de protección de la atmósfera, también cabe mencionar el Real Decreto 115/2017, de 17 de febrero, dictado al amparo del artículo 149.1.23 de la CE y que deroga el Real Decreto 795/2010, de 16 de junio, por el que se regula la comercialización y manipulación de gases fluorados y equipos basados en los mismos, así como la certificación de los profesionales que los utilizan. Su objeto es regular la distribución y puesta en el mercado de gases fluorados, así como su manipulación y la de los equipos basados en su empleo a efectos del control de fugas o emisiones y de su desmontaje y recuperación de los gases, y establecer los procedimientos de certificación de los profesionales que los utilizan, con el objetivo de evitar las emisiones a la atmósfera y dar cumplimiento a lo previsto en la normativa europea. Asimismo, establecer los requisitos técnicos para las instalaciones que desarrollen actividades actividades potencialmente contaminadoras de la atmósfera, con el fin de evitar la emisión de gases fluorados. 
Sumari: 1. Introducció. 2. El nou Text refós de la llei de prevenció i control integrats de la contaminació. 3. La reestructuració dels departaments ministerials: el nou Ministeri d'Agricultura i Pesca, Alimentació i Medi Ambient. 4. Novetats normatives en àmbits sectorials. 4.1. Sobre patrimoni natural i biodiversitat. 4.2. Sobre residus. 4.3. Sobre aigües. 4.4. Sobre protecció de l'atmosfera.

\section{INTRODUCCIÓ}

Durant el període objecte d'anàlisi (de l'1 d'octubre de 2016 al 30 de març de 2017), en l'àmbit estatal s'ha recuperat l'activitat normativa des del punt de vista ambiental, una vegada constituït el nou govern al mes de novembre passat, després de gairebé un any de govern en funcions. Ara bé, la pràctica totalitat de les normes adoptades tenen rang reglamentari —amb l'única excepció del Reial decret legislatiu 1/2016, de 16 de desembre, pel qual s'aprova el Text refós de la llei de prevenció i control integrats de la contaminació-, i, en general, o procedeixen a desplegar determinats aspectes de normes de rang legal pendents de desplegar, o bé responen no tant a l'aprovació de normes completament noves, sinó a la modificació de normes ja existents, per millorar la regulació que recullen.

La prevalença de normes reglamentàries revela que la tònica predominant continua sent l'aprovació de normes reglamentàries amb caràcter de legislació bàsica pel que fa a medi ambient, possibilitat que, tot i que admesa pel Tribunal Constitucional amb caràcter excepcional, "sempre que resultin imprescindibles $\mathrm{i}$ es justifiquin pel seu contingut tècnic o pel seu caràcter conjuntural, estacional o circumstancial $i$, en suma, sotmès a canvis o variacions freqüents $i$ inesperades (SSTC 102/1995, de 26 de juny, FJ 8; i STC 306/2000, de 12 de desembre, FJ $6)^{16}$, ha acabat generalitzant-se des del punt de vista ambiental. Entre les normes reglamentàries aprovades en aquest període destaquem, en particular, les que s'han aprovat pel que fa a patrimoni natural i biodiversitat, residus, aigües i protecció de l'atmosfera, i, a més a més, les que afecten l'estructura orgànica del Ministeri d'Agricultura i Pesca, Alimentació i Medi Ambient.

Així mateix, en l'àmbit internacional, destaca la ratificació per part d'Espanya de l'Acord de París, fet a París el 12 de desembre de 2015, que s'havia signat a

${ }^{16}$ Vid., per exemple, la Sentència 161/2014, de 7 d'octubre de 2014, FJ 7è. 
Nova York el dia 22 d'abril de $2016^{17}$, i l'objecte del qual és reforçar la resposta mundial a l'amenaça del canvi climàtic, en el context del desenvolupament sostenible i dels esforços per eradicar la pobresa.

\section{EL NOU TEXT REFÓS DE LA LLEI DE PREVENCIÓ I CONTROL INTEGRATS DE LA CONTAMINACIÓ}

El Govern, mitjançant el Reial decret legislatiu 1/2016, de 16 de desembre, de conformitat amb l'habilitació prevista en la disposició final 2a de la Llei 5/2013, d'11 de juny, per la qual es va modificar la Llei 16/2002, d'1 de juliol, de prevenció i control integrats de la contaminació ${ }^{18}$, ha aprovat el Text refós de la llei de prevenció i control integrats de la contaminació, i ha integrat en un únic text legal la Llei 16/2002 i les modificacions successives ${ }^{19}$, amb la finalitat de millorar la qualitat normativa i la seguretat jurídica en aquest àmbit. Aquest text refós, d'acord amb la disposició final 2a, té la consideració de legislació bàsica sobre protecció del medi ambient d'acord amb el que determina l'article 149.1.23 de la $\mathrm{CE}$, si bé el que estableix la disposició final 1a i les referències a la gestió de les conques intercomunitàries tenen el fonament constitucional en l'article 149.1.22 de la CE, que atorga a l'Estat la competència exclusiva sobre la legislació, l'ordenació i la concessió de recursos i aprofitaments hidràulics quan les aigües discorren per més d'una comunitat autònoma.

Tal com posa de manifest el preàmbul, "En nom de la coherència normativa que deriva del principi constitucional de seguretat jurídica, a més de recollir en un únic instrument normatiu la regulació canviant en la matèria, ha calgut

\footnotetext{
${ }^{17}$ Instrument de ratificació de l'Acord de París, fet a París el 12 de desembre de 2015 (BOE núm. 28, de 2 de febrer de 2017).

${ }^{18}$ La disposició final 2a de la Llei 5/2013 va ser modificada per la Llei 21/2015, de 20 de juliol, per la qual es va modificar la Llei 43/2003, de 21 de novembre, de forests.

${ }^{19}$ Produïdes per mitjà de les normes de rang legal següents: la Llei 1/2005, de 9 de març, per la qual es regula el règim del comerç de drets d'emissió de gasos d'efecte hivernacle; la Llei 27/2006, de 18 de juliol, per la qual es regulen els drets d'accés a la informació, de participació pública i d'accés a la justícia en matèria de medi ambient; la Llei 34/2007, de 15 de novembre de qualitat de l'aire i protecció de l'atmosfera; la Llei 42/2007, de 13 de desembre, del patrimoni natural i de la biodiversitat; la Llei 40/2010, de 29 de desembre, d'emmagatzematge geològic de diòxid de carboni; el Reial decret llei 8/2011, d'1 de juliol, de mesures de suport als deutors hipotecaris, de control de la despesa pública i cancel-lació de deutes amb empreses i autònoms contretes per les entitats locals, de foment de l'activitat empresarial i impuls de la rehabilitació i de simplificació administrativa; i la Llei 5/2013, d'11 de juny, per la qual es modifiquen la Llei 16/2002, d'1 de juliol, de prevenció i control integrats de la contaminació i la Llei 22/2011, de 28 de juliol, de residus i sòls contaminats.
} 
harmonitzar el contingut dels articles, de manera que s'ha ajustat la numeració dels articles i, per tant, les remissions i concordances entre si." A més, aquest reial decret legislatiu actualitza totes les referències normatives que inclou i, respectant les normes que han de ser objecte de refosa, introdueix alguns retocs menys importants per assolir una norma amb la màxima claredat ${ }^{20}$.

Entre els canvis ${ }^{21}$ que s'introdueixen en aquest text refós, en destaquem especialment dos, relatius a la coordinació de l'autorització ambiental integrada amb el règim aplicable a les activitats classificades i al règim sancionador. D'una banda, l'article 29 del Text refós modifica les previsions que anteriorment contenia l'article 28 de la Llei 16/2002 en relació amb la coordinació entre l'autorització ambiental integrada i el règim aplicable pel que fa a activitats classificades. El nou article 29 preveu que el procediment per atorgar l'autorització ambiental integrada "preval sobre qualsevol altre mitjà d'intervenció administrativa en l'activitat dels ciutadans que puguin establir les administracions competents per a l'exercici d'activitats molestes insalubres, nocives i perilloses". En canvi, l'article 28 de la Llei 16/2002, preveu que l'autorització ambiental integrada "ha de substituir els mitjans d'intervenció administrativa en l'activitat dels ciutadans que puguin establir les Administracions competents per a l'exercici d'activitats molestes, insalubres, nocives i perilloses", encara que precisa —en l'apartat 2 del mateix art. 28-que això s'entén "sense perjudici de les normes autonòmiques sobre activitats classificades que, si escau, siguin aplicables" - precisió que ara ha desaparegut en l'art. 29-, per la qual cosa respectava la possibilitat que la normativa autonòmica mantingués l'existència d'ambdues autoritzacions. Ara, s'afirma la prevalença — no la substitució- de l'autorització ambiental integrada sobre les llicències d'activitats classificades que puguin establir les administracions competents. D'altra banda, en l'article 29 del Text refós es manté la previsió recollida anteriorment en l'article 28 de la Llei 16/2002, que establia que “l'autorització ambiental integrada és, si escau,

\footnotetext{
${ }^{20}$ Així ho posa de manifest Blanca Lozano Cutanda, "El nuevo texto refundido de la ley de prevención y control integrados de la contaminación: mejora normativa y algún retoque", en Diario La Ley, núm. 8947, Secció Tribunal, 23 de març de 2017, p. 2.

${ }^{21}$ Pot veure's una anàlisi més completa de les novetats incorporades per aquest text refós en els treballs seguients: Antonio Cano Murcia, "Notas y comentarios al Texto Refundido de la Ley de Prevención y Control Integrados de la Contaminación", en El Consultor de los Ayuntamientos, núm. 3, 2017, de 15 de febrer de 2017, pp. 1-6; i Lozano Cutanda, "El nuevo..." cit., pp. 1-5.
} 
vinculant per a l'autoritat local quan impliqui la denegació de l'exercici de les activitats o la imposició de mesures correctores, així com tot el referent a tots els aspectes mediambientals que recull l'article 22 ".

D'altra banda, s'introdueixen algunes modificacions en el règim sancionador. Així, en l'article 31, als apartats 2 i 3, que recullen les infraccions molt greus i greus, s'introdueix una precisió quant a la tipificació de les infraccions recollides en l'apartat $c$ i s'indica que constitueix una infracció molt greu el fet d'incomplir les obligacions derivades de les mesures provisionals previstes en l'article 35 d'aquesta llei "quan suposi un perill greu per a la salut de les persones o el medi ambient" —incís ara afegit, no recollit en l'anterior art. 30.2.c de la Llei 16/2002_ ; i una infracció greu, el fet d'incomplir les obligacions derivades de les mesures provisionals previstes en l'article 35 "quan no suposi un perill greu per a la salut de les persones o el medi ambient" —incís també afegit, tampoc inclòs en l'anterior art. 30.3.c de la Llei 16/2002. D'altra banda, ara el Text refós imposa, en l'article 36.1, a tots els infractors l'obligació d'”adoptar les mesures complementàries que l'òrgan competent consideri necessàries per tornar a assegurar el compliment de les condicions de l'autorització ambiental integrada i per evitar altres possibles incidents o accidents", novetat important, ja que, anteriorment, la Llei 16/2002, únicament imposava aquesta obligació —en l'art. 31.1.b- als qui havien comès una infracció greu.

\section{LA REESTRUCTURACIÓ DELS DEPARTAMENTS MINISTERIALS: EL NOU MINISTERI D'AGRICULTURA I PESCA, ALIMENTACIÓ I MEDI AMBIENT}

Des del punt de vista organitzatiu, per mitjà del Reial decret 415/2016, de 3 de novembre, s'han reestructurat els departaments ministerials. Des de la perspectiva que aquí ens interessa, el gruix de competències ambientals es concentra ara en el Ministeri d'Agricultura i Pesca, Alimentació i Medi Ambient, ja que l'anterior Ministeri d'Agricultura, Alimentació i Medi Ambient s'ha suprimit. A aquest ministeri li correspon la proposta i execució de la política del Govern pel que fa a recursos agrícoles, ramaders i pesquers, d'indústria agroalimentària i de desenvolupament rural; i la proposta i execució de la política del Govern sobre medi ambient. 
L'estructura orgànica bàsica del nou Ministeri d'Agricultura i Pesca, Alimentació i Medi Ambient s'ha definit en el Reial decret 424/2016, d'11 de novembre, pel qual s'estableix l'estructura orgànica bàsica de tots els departaments ministerials. Aquest ministeri s'estructura en els òrgans superiors i directius següents: la Secretaria d'Estat de Medi Ambient, de la qual depenen la Direcció General de l'Aigua, l'Oficina Espanyola del Canvi Climàtic —amb rang de direcció general-, la Direcció General de Qualitat i Avaluació Ambiental i Medi Natural, i la Direcció General de Sostenibilitat de la Costa i del Mar; la Secretaria General d'Agricultura i Alimentació, de la qual depenen la Direcció General de Produccions i Mercats Agraris, la Direcció General de Sanitat de la Producció Agrària, la Direcció General de la Indústria Alimentària i la Direcció General de Desenvolupament Rural i Política Forestal; i la Sotssecretaria d'Agricultura i Pesca, Alimentació i Medi Ambient, de la qual depenen la Secretaria General Tècnica i la Direcció General de Serveis; i la Secretaria General de Pesca, de la qual depenen la Direcció General d’Ordenació Pesquera i la Direcció General de Recursos Pesquers i Aqüicultura.

\section{NOVETATS NORMATIVES EN ÀMBITS SECTORIALS}

En el període objecte d'anàlisi s'han aprovat nombroses normes de rang reglamentari des del punt de vista ambiental, en àmbits sectorials diversos. Atesa la impossibilitat d'analitzar-les totes, ens limitem a destacar les que ens han semblat especialment rellevants pel que fa a patrimoni natural i biodiversitat, residus, aigües i protecció de l'atmosfera.

\subsection{Sobre patrimoni natural i biodiversitat}

En aquest àmbit, cal destacar, en primer lloc, dues normes aprovades pel que fa a parcs nacionals, dictades a l'empara de l'article 149.1.23 de la CE, que atribueix a l'Estat la competència de legislació bàsica sobre protecció del medi ambient, sense perjudici de les facultats de les comunitats autònomes d'establir normes addicionals de protecció ${ }^{22}$. D'una banda, el Reial decret 389/2016, de 22

\footnotetext{
${ }^{22}$ Encara que amb algun matís en el cas del Reial decret 389/2016, de 22 d'octubre, la primera disposició final del qual també invoca altres títols competencials en relació amb determinades matèries. En efecte, preveu que la planificació socioeconòmica dels parcs nacionals prevista en el nou Pla Director es dicta a l'empara de l'article 149.1.13 de la CE, que atribueix a l'Estat la competència exclusiva en matèria de bases i coordinació de la planificació general de l'activitat econòmica; i que els criteris recollits en el Pla Director
} 
d'octubre, pel qual s'aprova el Pla Director de la Xarxa de Parcs Nacionals, i que substitueix i deroga el que anteriorment regulava el Reial decret 1803/1999, de 26 de novembre, a fi d'adaptar-ho a les noves previsions de la Llei 30/2014, de 3 de desembre, de parcs nacionals ${ }^{23}$. Aquest pla constitueix un instrument bàsic d'ordenació de la Xarxa de Parcs Nacionals i es configura com "l'instrument de planificació i ordenació d'aquests espais de caràcter bàsic més elevat” (art. 19 Llei 30/2014) i té "el caràcter de directrius bàsiques per a la planificació, conservació i coordinació dels parcs nacionals d'acord amb el que disposa l'article 19, apartats 1.d i 2 de la Llei 30/2014, de 3 de desembre, de parcs nacionals, i de directrius bàsiques de la legislació de protecció del medi natural, d'acord amb el que disposa l'article 17, apartats 2 i 3 de la Llei 42/2007, de 13 de desembre, del patrimoni natural i de la biodiversitat" (art. 2 del Reial decret 389/2016). Els plans rectors d'ús i gestió vigents han d'adaptar-se a aquest pla director en el termini de dos anys des de la seva entrada en vigor, d'acord amb el que disposa la disposició addicional 3 a de la Llei 30/2014; i els que es trobin en fase d'elaboració per l'administració competent de cada parc nacional, s'han d'adaptar a aquest pla director.

I de l'altra, el Reial decret 598/2016, de 5 de desembre, pel qual es regula la composició, funcions i funcionament del Consell de la Xarxa de Parcs Nacionals, òrgan col·legiat de caràcter consultiu, adscrit al Ministeri d'Agricultura i Pesca, Alimentació i Medi Ambient.

En segon lloc, és de referència obligada el Reial decret 599/2016, de 5 de desembre, pel qual es regula la llicència d'ús de la marca "Reservas de la Biosfera Española”. Des del punt de vista del títol competencial estatal que serveix de base per a l'aprovació d'aquesta norma, el que estableix la disposició final 1a crida l'atenció i suscita certa perplexitat, ja que, si bé declara que "es dicta en virtut de la competència estatal en matèria de legislació bàsica sobre

per determinar l'existència d'un greu perill per a la integritat i la seguretat d'un parc nacional, així com les directrius per a les actuacions en les situacions d'estat d'emergència declarat, s'emparen en la competència en matèria de seguretat pública, atribuïda a l'Estat amb caràcter exclusiu per l'article 149.1.29 de la CE.

${ }^{23}$ Poden veure's algunes de les novetats d'aquest Pla Director de la Xarxa de Parcs Nacionals, en particular quant als drets dels particulars afectats per la declaració de parc nacional, a Blanca Lozano Cutanda, "Real Decreto 389/2016: los derechos de los particulares en los parques nacionales según el nuevo plan director", en Análisi GA\&P, març 2017 (<http://www.gomezacebo-pombo.com/media/k2/attachments/real-decreto389-2016-los-derechos-de-los-particulares-en-los-parques-nacionales-segun-el-nuevo-plan-director.pdf $>$ [Última consulta, 9 d'abril de 2017]). 
protecció del medi ambient de conformitat amb el que disposa l'article 149.1.23 de la Constitució", a continuació afirma que "no constitueix legislació bàsica sinó que es dicta en exercici de les competències de desplegament i execució de l'article 149.1.23 que corresponen a l'Estat per a l'abast internacional d'aquesta matèria" 24. Quant al contingut, aquest reial decret regula la llicència d'ús de la marca "Reservas de la Biosfera Españolas", i estableix les normes i els requisits per a la concessió, manteniment i extinció. L'objecte d'aquesta marca és destacar i diferenciar "els productes naturals i artesanals dels territoris reconeguts com a reserves de la biosfera i els productes elaborats o serveis d'empreses donades d'alta en algun dels municipis que pertanyen a les reserves i que contribueixen a una o més de les funcions bàsiques que han de complir les reserves de la biosfera (conservació, desenvolupament i suport logístic), així com que estiguin d'acord amb el pla de gestió de la corresponent reserva de la biosfera, i respectar així les singularitats de cadascuna" (art. 3). Per això, els productes o serveis han de complir una sèrie de criteris i han de proveir-se amb la qualitat definits en aquest reglament, i ser respectuosos des del punt de vista ambiental. Així mateix, qualsevol producte o servei susceptible de ser diferenciat per les marques específiques de cada reserva, al seu torn pot obtenir la llicència d'ús de la marca "Reservas de la Biosfera Españolas", sempre que compleixin les premisses bàsiques de qualitat i procedència descrites en aquest reglament. L'Organisme Autònom Parcs Nacionals és el titular d'aquesta marca, en virtut de la seva inscripció a l'Oficina Espanyola de Patents i Marques, i l'òrgan de control responsable del bon ús de la marca, com a titular.

En tercer lloc, mitjançant el Reial decret 124/2017, de 24 de febrer, relatiu a l'accés als recursos genètics procedents de taxons silvestres i al control de la

\footnotetext{
${ }^{9}$ No aporta més aclariments en aquest punt la Memòria abreujada d'anàlisi de l'impacte normatiu del Projecte d'ordre per la qual es regula la llicència d'ús de la marca "Reservas de la Biosfera Españolas", que es limita a preveure que "la regulació del règim jurídic i el procediment de concessió de la llicència d'ús de l'esmentada marca s'ha de fer en una norma segons la competència estatal pel que fa a la legislació bàsica sobre protecció del medi ambient, prevista per l'article 149.1.23a de la Constitució, si bé, en aquest cas, no es tracta de legislació bàsica sinó que l'ordre es dicta en exercici de les competències de desenvolupament i execució de l'esmentat article constitucional que corresponen a l'estat per l'abast internacional d'aquesta matèria" (pàg. 5). El Consell d'Estat tampoc ha qüestionat el títol competencial invocat per l'Estat, en el Dictamen 235/2016, de 14 d'abril de 2016, afirmant que "El títol competencial previst en el preàmbul —el article 149.1.23 de la Constitució espanyola, en exercici de les competències de desenvolupament i execució de l'esmentat article que corresponen a l'Estat per l'abast internacional d'aquesta matèria- és correcte i no suscita cap problemàtica, ja que es tracta d'una marca d'àmbit nacional"' (apartat III).
} 
utilitzación ${ }^{25}$, es despleguen els articles 71, 72, 74, 80 i 81 de la Llei 42/2007, de 13 de desembre, del patrimoni natural i de la biodiversitat; i s'assegura la correcta utilització dels recursos genètics, de conformitat amb el Reglament (UE) n. 511/2014 del Parlament europeu i del Consell, de 16 d'abril, relatiu a les mesures de compliment dels usuaris del Protocol de Nagoya en la Unió i amb el Reglament d'execució (UE) 2015/1866 de la Comissió, de 13 d'octubre de 2015, pel qual s'estableixen normes detallades per a l'aplicació del Reglament (UE) $n$. $511 / 2014$. Així mateix, s'estableix addicionalment el sistema estatal d'informació sobre accés i utilització dels recursos genètics i coneixements tradicionals associats a Espanya, i es crea i es regula el Comitè sobre accés i utilització dels recursos genètics $\mathrm{i}$ coneixements tradicionals associats als recursos genètics a Espanya.

Finalment, mitjançant el Reial decret 199/2017, de 3 de març, s'ha aprovat el Reglament del Programa Nacional de Conservació i Utilització Sostenible dels Recursos Fitogenètics per a l'Agricultura i l'Alimentació, en desplegament del que estableixen els articles 48, 49, 50 i 51 de la Llei 30/2006, de 26 de juliol, de llavors i plantes de viver i de recursos fitogenètics, i s'ha creat la Comissió del Programa Nacional de Recursos Fitogenètics per a l'Agricultura i l'Alimentacióé.

\subsection{Sobre residus}

Pel que fa als residus, és de referència obligada el Reial decret 20/2017, de 20 de gener, sobre els vehicles al final de la seva vida útil, que té la consideració de legislació bàsica sobre planificació general de l'activitat econòmica i sobre protecció del medi ambient, d'acord amb el que disposa l'article 149.1.13 i 23 de la CE. Aquest reial decret deroga l'anterior Reial decret 1383/2002, de 20 de desembre, sobre gestió de vehicles al final de la seva vida útil, que va incorporar a l'ordenament jurídic espanyol la Directiva 2000/53/CE del Parlament europeu i

\footnotetext{
${ }^{10}$ Aquest reial decret també té caràcter de legislació bàsica sobre protecció del medi ambient, d'acord amb el que disposa l'article 149.1.23.a de la CE (disposició final 2a).

${ }^{11} \mathrm{D}$ 'acord amb la disposició final 1a, aquest reial decret es dicta a l'empara del que disposa l'article 149. 1, apartats 15 i 23, de la CE, que atribueix a l'Estat competència exclusiva sobre, respectivament, foment i coordinació general de la investigació científica i tècnica, i legislació bàsica sobre protecció del medi ambient, llevat dels preceptes relatius al manteniment i conservació dels recursos fitogenètics, que es dicten a l'empara del que disposa l'article $149.1 .13 a$ de la Constitució espanyola, que atribueix a l'Estat competència exclusiva sobre les bases i coordinació de la planificació general de l'activitat econòmica.
} 
del Consell, de 18 de setembre de 2000, relativa als vehicles al final de la seva vida útil.

La derogació del Reial decret 1383/2002 i la seva substitució pel nou Reial decret 20/2017 es justifiquen per una sèrie de circumstàncies que han tingut lloc durant el temps transcorregut des que s'ha adoptat: l'aprovació de la Llei 22/2011, de 28 de juliol, de residus i sòls contaminats, que ha introduït modificacions rellevants en el règim aplicable a la producció i gestió de residus, que fa necessària l'adaptació a les seves previsions de les normes reglamentàries de desplegament que s'adoptin; l'adopció per part de la Comissió de la Decisió 2005/293, d'1 d'abril de 2005, per la qual s'estableixen normes per controlar el compliment dels objectius de reutilització i valorització així com de reutilització i reciclatge establerts en la Directiva 2000/53/CE; i la constatació, gràcies a l'experiència adquirida durant la seva aplicació, de l'existència d'alguns aspectes de la regulació que cal millorar, com la definició de l'àmbit d'aplicació de la norma i la seva coherència amb els règims d'altres fluxos de residus.

Partint d'aquestes premisses, el Reial decret 20/2017 s'aprova a fi d'establir mesures destinades a la prevenció de la generació de residus procedents de vehicles i a la recollida, a la preparació per a la reutilització, al reciclatge i altres formes de valorització dels vehicles al final de la seva vida útil, inclosos els seus components, per reduir l'eliminació de residus i millorar l'eficàcia en la protecció de la salut humana i del medi ambient al llarg del cicle de vida dels vehicles. D'aquesta forma, es regulen, s'adapten i se sistematitzen tots els aspectes relacionats amb els vehicles al final de la seva vida útil, d'acord amb la Directiva 2000/53/CE i la Llei 22/2011. Essencialment, tal com posa de manifest el preàmbul, es manté la regulació preexistent sobre els vehicles al final de la seva vida útil i se'n conserven els elements fonamentals: la definició de vehicle; les obligacions dels productors o fabricants de vehicles; l'obligació dels usuaris de lliurar els vehicles a un centre de tractament, bé directament, bé per mitjà d'una instal-lació de recepció; l'obligació de documentar el lliurament per mitjà del certificat de destrucció que acredita la fi de la vida útil del vehicle; la tramitació pels centres de tractament de la baixa del vehicle, segons l'Ordre INT/624/2008, de 26 de febrer; l'exigència del compliment de requisits tècnics d'emmagatzematge i tractament; i l'obligació dels agents econòmics de 
compliment d’objectius de preparació per a la reutilització, reciclatge i valorització.

Ara bé, també s'introdueixen novetats pel que fa al reial decret que es deroga ${ }^{27}$. Les principals deriven de la necessitat d'adaptar-ne les previsions a la Llei 22/2011, especialment pel que fa a la jerarquia de residus, la responsabilitat ampliada del productor i les obligacions d'informació. Així, se'n precisa l'àmbit d'aplicació; es regulen amb més detall les operacions que han de realitzar els centres autoritzats per al tractament dels vehicles al final de la seva vida útil i els requisits que han de complir les instal-lacions; s'adopten mesures per evitar que es produeixi un doble finançament de la gestió dels vehicles o dels seus components; es completen algunes previsions sobre les obligacions a les quals se sotmeten els productors i altres agents econòmics, incloses les d'informació, i sobre el règim sancionador; s'adequa aquest flux de residus a la Llei 22/2011, que inclou especialment la preparació per a la reutilització com a tractament i adapta els sistemes de responsabilitat ampliada del productor del producte al que preveu el títol IV; i s'afegeix una disposició addicional per regular la cessió temporal dels vehicles al final de la seva vida útil que s'han donat de baixa definitiva a la Direcció General de Trànsit per a formació, recerca, protecció civil o simulacres.

\subsection{Sobre aigües}

En l'àmbit de les aigües, la norma més rellevant que s'ha aprovat en aquest període és el Reial decret 638/2016, de 9 de desembre, pel qual es modifiquen el Reial decret 849/1986, d'11 d'abril, pel qual s'aprova el Reglament del domini públic hidràulic (d'ara endavant, RDPH); el Reial decret 907/2007, de 6 de juliol, pel qual s'aprova el Reglament de la planificació hidrològica (RPH); l'Ordre ARM/2656/2008, de 10 de setembre, per la qual s'aprova la instrucció de planificació hidrològica; el Reial decret 903/2010, de 9 de juliol, d'avaluació i gestió de riscos d'inundació, i el Reial decret 817/2015, d'11 de setembre, pel

\footnotetext{
12 Sobre les novetats introduïdes per aquest reial decret, vid. Pedro Poveda Gómez i Blanca Lozano Cutanda, "Real Decreto 20/2017, sobre los vehículos al final de su vida útil: análisis de sus novedades", en Análisis GA\&P, febrer de 2017 (<http://www.gomezacebo-pombo.com/media/k2/attachments/real-decreto-202017-sobre-los-vehiculos-al-final-de-su-vida-util-analisis-de-sus-novedades_2.pdf> [Última consulta, 9 de maig de 2017]).
} 
qual s'estableixen els criteris de seguiment i avaluació de l'estat de les aigües superficials i les normes de qualitat ambiental ${ }^{28}$.

Les modificacions afecten quatre àmbits d'actuació essencials, els quals es caracteritzen, com indica la Memòria de l'anàlisi d'impacte normatiu d'aquest reial decret, "per un eix conductor comú, que és l'experiència adquirida en l'aplicació dels plans hidrològics de conca, d'acord amb els calendaris establerts en la Directiva 2000/60 marc de l'aigua i els plans de gestió del risc d'inundació, d'acord amb la Directiva 2007/60, d'avaluació i gestió dels riscos d'inundació": gestió del risc d'inundacions, cabals ecològics, reserves hidrològiques i abocaments i qualitat de les aigües. Amb aquestes modificacions es persegueixen els objectius següents: millorar el tractament de la gestió del risc d'inundació, millorar la definició i el règim de compliment dels cabals ecològics, configurar el règim jurídic de les reserves hidrològiques per procedir a la declaració de les reserves hidrològiques existents en coordinació amb els plans hidrològics del segon cicle, i establir les bases del cens nacional d'abocaments.

En primer lloc, quant a la gestió del risc d'inundacions, aquesta modificació actualitza el marc normatiu vigent i millora el tractament de la gestió del risc d'inundació, resol les llacunes existents en la normativa vigent, en millora la regulació i garanteix l'adequada implantació i coordinació dels plans hidrològics de conca i els plans de gestió del risc d'inundació. De les modificacions introduïdes en aquesta matèria destaca la introducció d'una regulació detallada dels usos i construccions prohibits i permesos a les zones inundables dels llits del domini públic hidràulic. En particular, es concreten quins són els usos i construccions que no es poden autoritzar a les zones de flux preferent —segons es tracti de sòl rural o urbanitzat—, incloent determinats supòsits excepcionals; i en la resta de zones inundables ${ }^{29}$.

\footnotetext{
13 D'acord amb la disposició final 1a, el Reial decret 638/2016 té caràcter de legislació bàsica sobre protecció del medi ambient, d'acord amb el que disposa l'article 149.1.23 CE, excepte els apartats 1 a 8 , 11 a 13, 31 i 32 de l'article primer, que es dicten conjuntament l'empara del 149.1.29 de la Constitució, que atribueix a l'Estat la competència exclusiva sobre seguretat pública; i l'apartat 16 quant a l'article 244 3 r.2 i següents; l'apartat 19 pel que fa a l'article 254.1 i 254 bis.1; i els apartats 26 I 27, tots de l'article primer, que es dicten en virtut de l'article 149.1.22 CE, que atribueix a l'Estat la competència exclusiva sobre la legislació, ordenació i concessió de recursos i aprofitaments hidràulics si les aigües passen per més d'una comunitat autònoma.

${ }^{29}$ Sobre aquesta qüestió, vid. Blanca Lozano Cutanda i Carlos Vázquez Cobos, "Real Decreto 638/2016: regulación de los usos y construcciones en las zonas inundables de los cauces”, en Análisis GA\&P, març
} 
En segon lloc, en relació amb els cabals ecològics, es precisen i es milloren determinats aspectes del seu règim jurídic, tant de la seva definició jurídica, com del manteniment, control i seguiment pels diversos organismes de conca.

En tercer lloc, pel que fa a les reserves hidrològiques, s'introdueix una regulació nova, per mitjà de la modificació del RDPH, que millora la definició d'aquesta figura i les mesures de gestió associades. En particular, es defineixen les característiques per declarar les reserves hidrològiques $\mathrm{i}$ els conceptes dels subtipus que les integren; es determina el règim de protecció de les reserves hidrològiques i el conjunt de mesures per a la seva gestió; i es defineix el Catàleg nacional de reserves hidrològiques per donar suport a tota la informació tècnica que possibiliti l'adequada descripció física de les reserves hidrològiques.

Finalment, en relació amb els abocaments, les modificacions dutes a terme recullen aspectes relatius a l'organització i funcionament del Cens Nacional d'Abocaments, per adaptar-se a la Llei 27/2006, de 18 de juliol, reguladora dels drets d'accés a la informació, de participació pública i accés a la justícia en matèria de medi ambient. A més, es concreta la destinació del cànon de control d'abocament per reforçar-ne el caràcter finalista. Finalment, amb altres modificacions relatives als abocaments, es pretén augmentar l'eficàcia de l'Administració, mitjançant la simplificació dels procediments i la reducció de càrregues administratives per als titulars d'abocaments poc contaminants $i$ millorar la protecció de les aigües enfront d'abocaments generats per residus industrials o miners.

Pel que fa a aigües, també es pot destacar l'Ordre AAA/1760/2016, de 28 d'octubre, per la qual es regula l'estructura informàtica del Registre d'Aigües i de la Base Central de l'Aigua. Per mitjà d'aquesta norma, aplicable al Ministeri d'Agricultura i Pesca, Alimentació i Medi Ambient, els organismes de conca i les administracions hidràuliques de les comunitats autònomes que tinguin transferides les seves competències, es determina l'estructura informàtica que conforma el Registre d'Aigües Electrònic, regulat mitjançant el RDPH, des de la seva modificació pel Reial decret 670/2013, de 6 de setembre; i el contingut,

2017 (<http://www.gomezacebo-pombo.com/media/k2/attachments/real-decreto-638-2016-regulaciyn-delos-usos-y-construcciones-en-las-zonas-inundables-de-los-cauces.pdf > [Última consulta, 9 de maig de 2017]). 
l'estructura informàtica i els modes d'interoperabilitat de la Base Central de l'Aigua amb els sistemes d'informació que en formen part.

\subsection{Sobre protecció de l'atmosfera}

Per mitjà del Reial decret 39/2017, de 27 de gener, s'ha modificat el Reial decret 102/2011, de 28 de gener, relatiu a la millora de la qualitat de l'aire, que defineix i estableix objectius de qualitat de l'aire per als contaminants atmosfèrics amb més incidència en la salut de les persones i en el medi ambient; i, a més, regula l'avaluació, el manteniment i la millora de la qualitat de l'aire, amb l'establiment de mètodes i criteris comuns d'avaluació, i determina la informació que s'han d'intercanviar les administracions públiques per complir el deure d'informació a la Comissió Europea, així com la informació que cal posar a disposició del públic ${ }^{30}$.

Aquesta modificació es justifica en tres raons fonamentals. En primer lloc, en la necessitat d'incorporar a l'ordenament jurídic espanyol la Directiva adoptada per la Comissió Europea 2015/1480, de 28 d'agost de 2015, per la qual es modifiquen diversos annexos de la Directiva 2004/107/CE del Parlament Europeu i del Consell, de 15 de desembre de 2004, relativa a l'arsènic, el cadmi, el mercuri, el níquel i els hidrocarburs aromàtics policíclics en l'aire ambient, i la Directiva 2008/50/CE del Parlament europeu i del Consell, de 21 de maig de 2008, relativa a la qualitat de l'aire ambient i a una atmosfera més neta a Europa. S'hi estableixen les normes relatives als mètodes de referència, la validació de dades i la ubicació dels punts de mesurament, per a l'avaluació de la qualitat de l'aire ambient, que s'han d'incorporar.

En segon Iloc, en la voluntat d'eliminar una obligació que havia incorporat el Reial decret 812/2007, de 22 de juny, sobre avaluació i gestió de la qualitat de l'aire ambient en relació amb l'arsènic, el cadmi, el mercuri, el níquel i els hidrocarburs aromàtics policíclics, i que s'havia mantingut en el Reial decret 102/2011, de mesurament del mercuri particulat i del mercuri gasós divalent, a pesar que

\footnotetext{
${ }^{15}$ El Reial decret 102/2011, d'acord amb la seva disposició final 2a, es dicta a l'empara de les competències exclusives que a l'Estat atorga l'article 149.1.16 I 23 de la Constitució, en matèria de bases i coordinació general de la sanitat i de legislació bàsica sobre protecció del medi ambient.
} 
aquest mesurament es recollia com una mera recomanació en la Directiva 2004/107/CE.

En tercer lloc, en la necessitat de corregir un error en la transposició de la Directiva 2008/50/CE, consistent en la confusió entre i-hexà i i-hexè comesa a l'apartat II de l'annex XI.

A la vista del que hem exposat, les principals modificacions que comporta aquest reial decret es refereixen als objectius de qualitat de les dades relatives al benzo(a)pirè, arsènic, cadmi i níquel, hidrocarburs aromàtics policíclics (HAP) diferents del benzo(a)pirè, mercuri gasós total i dipòsits totals. Així mateix, es pretén garantir l'adequada avaluació de la qualitat de l'aire ambient pel que fa al diòxid de sofre, diòxid de nitrogen i òxids de nitrogen, monòxid de carboni, benzè, partícules i plom, així com la microimplantació dels punts de mesurament d'aquests contaminants, i regular els requisits per a la documentació i reavaluació de l'elecció dels emplaçaments. D'altra banda, les modificacions també afecten els mètodes de referència per a l'avaluació de les concentracions de diòxid de sofre, diòxid de nitrogen i òxids de nitrogen, partícules (PM10 i PM2,5), plom, benzè, monòxid de carboni i ozó, arsènic, cadmi, mercuri, níquel i HAP; la normalització i informes d'assaig; els criteris de determinació del nombre mínim de punts per al mesurament fix de les concentracions d'ozó; la rectificació de la necessitat de determinació de mercuri particulat i de mercuri gasós divalent; i l'establiment de les bases per al futur desplegament reglamentari d'un índex de qualitat de l'aire nacional.

A més, es concreten les competències del Ministeri d'Agricultura i Pesca, Alimentació i Medi Ambient, per mitjà de l'Agència Estatal de Meteorologia, pel que fa a informació sobre la superació dels llindars establerts en les estacions de mesurament sota la seva gestió.

Pel que fa a la protecció de l'atmosfera, també cal esmentar el Reial decret 115/2017, de 17 de febrer, dictat a l'empara de l'article 149.1.23 de la CE i que deroga el Reial decret 795/2010, de 16 de juny, pel qual es regula la comercialització i manipulació de gasos fluorats i equips que s'hi basen, així com la certificació dels professionals que els utilitzen. El seu objecte és regular la distribució i posada al mercat de gasos fluorats, així com la seva manipulació i la 
dels equips basats en la seva ocupació a l'efecte del control de fugides o emissions i del seu desmuntatge i recuperació dels gasos, i establir els procediments de certificació dels professionals que els utilitzen, amb l'objectiu d'evitar les emissions a l'atmosfera i complir el que preveu la normativa europea. I establir els requisits tècnics per a les instal-lacions que duguin a terme activitats potencialment contaminadores de l'atmosfera, amb la finalitat d'evitar l'emissió de gasos fluorats. 